\title{
Regulation of Renal LAT2 and 4F2hc Expression by Aldosterone
}

\author{
Maria João Pinho, João S. Amaral, Vanda Pinto, Maria Paula Serrão and Patrício Soares-da-Silva*
}

Institute of Pharmacology and Therapeutics, Faculty of Medicine, University of Porto, 4200-319 Porto, Portugal

\begin{abstract}
In the spontaneous hypertensive rat, overexpression of the renal $\mathrm{Na}^{+}$-independent L-amino acid transporter LAT2 is organ specific, precedes the onset of hypertension, correlates negatively with plasma aldosterone, and parallels the enhanced ability to take up L-DOPA and form renal dopamine. The present study evaluated the role of aldosterone on transcript and protein abundance of $\mathrm{Na}^{+}$-independent and $\mathrm{Na}^{+}$-dependent amino acid transporters. $\mathrm{Na}^{+}$-independent heterodimeric amino acid transporters LAT1/4F2hc, LAT2/4F2hc and a $\mathrm{Na}^{+}$-dependent transporter ASCT2 transcript and protein abundance was determined in the renal cortex of normotensive Wistar rats chronically treated with aldosterone $(1.5 \mathrm{mg})$, spironolactone $(200 \mathrm{mg})$ or aldosterone plus spironolactone. Aldosterone significantly increased renal cortical LAT2 mRNA levels (45\% increase), with no changes in LAT1, 4F2hc and ASCT2 transcript levels. The effect of aldosterone upon LAT2 mRNA levels was completely prevented by spironolactone. At the protein level, aldosterone treatment did not significantly affect LAT1 and LAT2 expression, but markedly reduced (51\% decrease) the abundance of 4F2hc and the urinary excretion of dopamine and DOPAC. The effect of aldosterone upon $4 \mathrm{~F} 2 \mathrm{hc}$ protein abundance was not reversed by spironolactone. Increases in renal LAT2 transcript during chronic treatment with aldosterone occur through a spironolactone-sensitive genomic mechanism. This effect parallels with a decrease in LAT2 functionality, resulting from decreases in 4F2hc protein abundance, which appears to be either a non-genomic effect or an indirect effect of aldosterone. The decrease in LAT2 functionality by aldosterone correlates well with the reduction in urinary dopamine.
\end{abstract}

Keywords: LAT2, 4F2hc, aldosterone, LAT1, ASCT2, dopamine.

\section{INTRODUCTION}

Amino acid transporters are abundantly expressed in the renal epithelia, but information on the mechanisms regulating their activity is still scarce. Several factors have been indicated as potential modulators of amino acid transport activity or expression, namely, osmotic shock, metabolic acidosis, cellular stress and hormones [1].

Steroid hormones have been shown to enhance or diminish amino acid transport depending on the nature of the hormone. Micropuncture studies revealed a glucocorticoidinducible transport system for neutral amino acids mainly located in proximal straight tubules of rat kidney [2]. Dexamethasone was found to induce both the activity and expression of transport system $\mathrm{y}^{+}$LAT1 $[2,3]$. ASUR4 is a Xenopus leavis LAT-type light chains reported to be induced at mRNA level by aldosterone in epithelial cells [4]. Additionally, in Xenopus oocytes LAT1 is associated with a nonselective cation channel that is regulated by the serum- and glucocorticoid-regulated kinase sgk1 [5]. It is known that sgk1 is involved in the mechanism of aldosterone to elevate renal $\mathrm{Na}^{+}$reabsorption, acting as an ENaC-regulating protein kinase.

The candidate transport systems for L-DOPA may include the $\mathrm{Na}^{+}$-dependent systems $\mathrm{B}^{0}, \mathrm{~B}^{0,+}$ and $\mathrm{y}^{+} \mathrm{L}$, and the $\mathrm{Na}^{+}$-independent systems L (LAT1 and LAT2) and $\mathrm{b}^{0,+}$

\footnotetext{
*Address correspondence to this author at the Institute of Pharmacology and Therapeutics, Faculty of Medicine, University of Porto, 4200-319 Porto, Portugal; Tel: 351-22-5513642; Fax: 351-22-5513643;
}

E-mail: psoaresdasilva@netcabo.pt
[6-11]. Our group has suggested that L-DOPA transport in immortalized renal proximal tubular epithelial (PTE) cells of the spontaneous hypertensive rat and its normotensive control Wistar-Kyoto rat is mediated by LAT2 [12] and demonstrated for the first time that overexpression of LAT2 in the SHR kidney is organ specific and precedes the onset of hypertension, this being accompanied by an enhanced ability to take up L-DOPA [13]. More recently, the presence of adaptive regulatory mechanisms of renal amino acid transporters in response to acute dietary $\mathrm{Na}^{+}$changes have been reported [14]. The transcript abundance of amino acid transporters LAT1, LAT2, B ${ }^{0}$ AT1 and ASCT2 was age dependent, differently regulated in WKY and SHR and responded differently to salt intake. In fact, the expression of LAT2 correlated negatively with plasma aldosterone levels after high sodium intake [14]. In heart failure patients, increases in plasma aldosterone, as a result of low salt intake or depending on the severity of the clinical condition, correlated positively with the ability of the kidney to form dopamine from circulating L-DOPA [15-17].

Because of the importance of L-type and ASC amino acid transporters in the uptake of L-DOPA, it is fundamental to understand the regulation of expression of these transporters in the kidney. The present study was aimed to assess whether aldosterone is involved in the physiological mechanism of regulation of amino acid transporters. For this purpose, we evaluated the transcript and protein abundance of $\mathrm{Na}^{+}$-independent heterodimeric amino acid transporters LAT1/4F2hc, LAT2/4F2hc and a $\mathrm{Na}^{+}$-dependent transporter ASCT2, in the renal cortex of normotensive Wistar rats chronically treated with aldosterone. 


\section{MATERIALS AND METHODOLOGY}

\section{Animal Interventions}

All animal interventions were performed in accordance with the European Directive number 86/609, and the rules of the "Guide for the Care and Use of Laboratory Animals", $7^{\text {th }}$ edition, 1996, Institute for Laboratory Animal Research (ILAR), Washington, DC. All animals were purchased from Harlan (Harlan-Inferfauna, Barcelona, Spain). Rats were kept under controlled environmental conditions $(12 \mathrm{~h}$ light/dark cycle and room temperature $22 \pm 2{ }^{\circ} \mathrm{C}$ ) and fluid intake and food consumption were monitored daily throughout the study. Blood pressure (systolic and diastolic) and heart rate were measured in conscious restrained animals, between 7.00 to 10.00 a.m., using a photoelectric tail cuff pulse detector (LE 5000, Letica, Barcelona, Spain).

Male Wistar rats of 8-weeks of age were randomly treated with one of the following combinations for 8 days: PALDO group, placebo for aldosterone pellet $(1.5 \mathrm{mg})$; ALDO group, aldosterone pellet (1.5 mg; 21-day release); PSPIRO group, placebo for spironolactone pellet (200 mg); SPIRO group, spironolactone pellet $(200 \mathrm{mg}$; 21-day release); PALDO+PSPIRO group, placebo for aldosterone pellet $(1.5 \mathrm{mg})$ and placebo for spironolactone pellet (200 $\mathrm{mg}$ ); ALDO+SPIRO group, aldosterone pellet (1.5 mg; 21day release) and spironolactone pellet (200 mg; 21-day release). Pellets (Innovative Research of America, Sarasota, FL) were implanted subcutaneously on dorsum of neck under sodium pentobarbital $\left(60 \mathrm{mg} \mathrm{kg}^{-1}\right.$, i.p.) anaesthesia. To keep the levels of endogenous aldosterone to a minimum, and allow the evaluation of exogenous administrated hormone, rats were submitted to high salt intake $(1 \% \mathrm{NaCl}$ in their drinking) for the duration of treatments [18-20].

After completion of each protocol, rats were anesthetized with sodium pentobarbital (60 $\mathrm{mg} \mathrm{kg}^{-1}$ i.p.). Blood removed from the left ventriculum was collected in tubes containing $\mathrm{K}_{3}$ EDTA. Kidneys were rapidly removed, rinsed free from blood with normal saline, the renal cortices were dissected out, snap-frozen in liquid nitrogen and stored at $-80^{\circ} \mathrm{C}$ until processing for RNA extraction.

\section{Plasma and Urine Ionogram and Biochemistry}

Plasma and urine sodium, potassium osmolality, and creatinine were measured using an automated analyzer (Hitachi 717, Boehringer Mannheim, Germany).

\section{Assay of Plasma Renin Activity (PRA) and Aldosterone}

Blood samples were collected in chilled $\mathrm{K}_{3}$ EDTA tubes. Plasma was separated and assayed aldosterone by radioimmunoassay (Diagnostic Products Corporation; Los Angeles, CA). PRA was measured by indirect RIA kit (DiaSorin, Stillwater, MN).

\section{Assay of Catecholamines}

The assay of dopamine and DOPAC in urine was performed by high pressure liquid chromatography with electrochemical detection, as previously described [21, 22]. The lower limit of detection of dopamine and DOPAC ranged from 350 to $1,000 \mathrm{fmol}$.

\section{RNA Extraction and Reverse Transcription}

Kidney cortices were homogenized (Diax, Heidolph) in Trizol Reagent (75mg ml $\mathrm{m}^{-1}$; Invitrogen) and total RNA was extracted according to manufacturer's instructions. The RNA obtained was dissolved in diethylpyrocarbonate (DEPC)treated water and quantified by spectrophotometry at 260 $\mathrm{nm}$.

Total RNA extracted from individual rat kidney cortices was treated with DNase (Ambion), to eliminate potential genomic DNA contamination. cDNA was synthesized from $1 \mu \mathrm{g}$ of total RNA in a total volume of $20 \mu \mathrm{l}$. Reverse transcription was performed with SuperScript First Strand System for RT-PCR (Invitogen), using $50 \mu \mathrm{g} \mu \mathrm{l}^{-1}$ random hexamers as primers at $50^{\circ} \mathrm{C}$, according to manufacture's instructions. For real-time quantitative PCR, $1 \mu$ lout of the 20 $\mu l$ reverse transcription reaction mixture was used.

\section{Standard Preparation}

Standards for amino acid transporters and GAPDH were obtained by conventional PCR amplification, using Platinum TaqPCRx DNA Polymerase (Life Technologies) and the following rat specific primers: LAT1 forward primer 5'-CTC CTT GCC CAT TGT CAC-3' and reverse primer 5'-GGT AGT TCC CAA AAT CCA CAG-3' (position 855 and 950 bp in rat LAT1 sequence AB015432); LAT2 forward primer 5'-TCG CTG TGA CTT TTG GAG AGA-3' and reverse primer 5'-CGG GAG GAG GTG AAG AGG-3' (position 908 and 1,002 bp in rat LAT2 sequence AB024400); 4F2hc forward primer 5'-GTC ACA GCC CGT TTT CAC T-3' and reverse primer 5'-CCT GCC TGC GAC ACA CTC C-3' (position 897 and $980 \mathrm{bp}$ in rat 4F2hc sequence NM_019283); ASCT2 forward primer 5'-CGT CCT CAC TCT TGC CAT CAT-3' and reverse primer 5'-CCA AAA GCA TCA CCC TCC AC-3' (position 1298 and 1427 bp in rat ASCT2 sequence NM_175758); and GAPDH forward primer 5'-GGC ATC GTG GAA GGG CTC ATG AC-3' and reverse primer 5'-ATG CCA GTG AGC TTC CCG TTC AGC-3' (position 716 and 800 bp in rat GAPDH sequence M17701). PCR products were gel purified with Qiaex II (Qiagen) and quantified by spectrophotometry at $260 \mathrm{~nm}$. The concentration was determined and the DNA was diluted accordingly in serial steps. PCR fragments were cloned and sequenced.

\section{Quantitative Real-Time PCR}

Real-time PCR was carried out using a LightCycler (Roche, Mannheim, Germany), as previously described [14]. Briefly, each RT-PCR reaction mixture $(50 \mu \mathrm{l})$ included reverse transcription products corresponding to $50 \mathrm{ng}$ of total RNA or standard DNA, 1 x SYBR Green I master mix

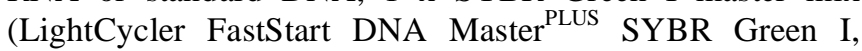
Roche), $0.5 \mu \mathrm{M}$ of each forward and reverse primers (described previously). Cycling conditions were as follows: denaturation $\left(95^{\circ} \mathrm{C}\right.$ for $\left.1 \mathrm{~min}\right)$, amplification and quantification $\left(95^{\circ} \mathrm{C}\right.$ for $10 \mathrm{~s}, 56^{\circ} \mathrm{C}-62^{\circ} \mathrm{C}$ for $10 \mathrm{~s}, 72^{\circ} \mathrm{C}$ for $5 \mathrm{~s}$, with a single florescence measurement at the end of the $72^{\circ} \mathrm{C}$ for $5 \mathrm{~s}$ segment) repeated 35 times, a melting curve program (65$95^{\circ} \mathrm{C}$ with a heating rate of $0.1^{\circ} \mathrm{C} \mathrm{s}^{-1}$ and continuous fluorescent measurement) and a cooling step to $40^{\circ} \mathrm{C}$. 
Amplification specificity was checked using melting curves following manufacture's instructions. In addition, PCR products were separated by electrophoresis in a $2 \%$ TBE agarose gel to confirm that correct band sizes. Results were analyzed with LightCycler Software v.3.5 (Roche Applied Science, Mannheim, Germany) using the second derivate maximum method. Quantification was performed using standard curves. Standards for all amplicons were obtained by conventional PCR amplification, using Platinum TaqPCRx DNA Polymerase (Life Technologies).

For each gene, a standard curve a line of best fit was generated using the five concentration data points. The calculated slope of the line $(\mathrm{m})$ was used to determine reaction efficiency with the following equation: $\mathrm{RE}=\left[10^{\wedge}(-\right.$ $1 / \mathrm{m})] / 2 * 100$. Using this equation, the reaction efficiency of SYBR Green RT-PCR reactions was $98.0 \pm 1.8 \%$. Data was normalized to the expression of the constitutively expressed gene GAPDH.

\section{Immunoblotting}

Renal cortical membranes were washed with PBS and then lysed in RIPA buffer containing $150 \mathrm{mM} \mathrm{NaCl}, 50 \mathrm{mM}$ Tris- $\mathrm{HCl}, \mathrm{pH} 7.4,5 \mathrm{mM}$ EDTA, $1 \%$ Triton $\mathrm{X}-100,0.5 \%$ sodium deoxycholate, $0.1 \%$ SDS, $100 \mu \mathrm{g} \mathrm{ml}^{-1}$ PMSF, $2 \mu \mathrm{g}$ $\mathrm{ml}^{-1}$ leupeptin and $2 \mu \mathrm{g} \mathrm{ml}^{-1}$ aprotinin. Protein concentration was determined using a protein assay kit (Bio-Rad Laboratories, Hercules, CA), with bovine serum albumin as standard. Cell lysates were boiled in sample buffer $(35 \mathrm{mM}$ Tris- $\mathrm{HCl}$, pH $6.8,4 \%$ SDS, $9.3 \%$ dithiothreitol, $0.01 \%$ bromophenol blue, $30 \%$ glycerol) at $95^{\circ} \mathrm{C}$ for $5 \mathrm{~min}$. Samples containing 30-60 $\mu \mathrm{g}$ of protein, were separated by SDS-PAGE with $10 \%$ polyacrylamide gel and then electroblotted onto nitrocellulose membranes (Bio-Rad). Blots were blocked for $1 \mathrm{~h}$ with $5 \%$ non-fat dry milk in PBS $\left(10 \mathrm{mmol} \mathrm{l}^{-1}\right.$ phosphatebuffered saline) at room temperature with constant shaking. Blots were then incubated with antibodies goat polyclonal anti-LAT2 (1:800; Santa Cruz Biotechnology); rabbit antiLAT1 (1:500; Serotec); rabbit polyclonal anti-ASCT2 (1:500; Chemicon International) or mouse monoclonal anti$\beta$-actin (1:1000; Santa Cruz Biotechnology), in 5\% non-fat dry milk in PBS-T overnight at $4^{\circ} \mathrm{C}$. The immunoblots were subsequently washed and incubated with fluorescentlylabeled goat anti-rabbit (1:10,000; IRDye ${ }^{\text {Tm }} 800$, Rockland) or the fluorescently-labeled goat anti-mouse secondary antibody (1:5,000; AlexaFluor 680, Molecular Probes) for 60 $\mathrm{min}$ at room temperature and protected from light. The membrane was washed and imaged by scanning at both 700 $\mathrm{nm}$ and $800 \mathrm{~nm}$, with an Odyssey Infrared Imaging System (LI-COR Biosciences).

\section{Statistical Methods}

Data are presented as means \pm SEM. Statistical significance was determined using one-way analysis of variance (ANOVA) followed by Newman-Keuls test for multiple comparisons. A P value less than 0.05 was assumed to denote a significant difference.

\section{RESULTS}

\section{Effect of Aldosterone Treatment on Blood Pressure and other Physiological Parameters}

Eight days after beginning of the treatment, body weights in the ALDO and ALDO+SPIRO groups were slightly, but significantly $(\mathrm{P}<0.05)$, higher than the corresponding placebo groups (Table 1). In the ALDO and ALDO+SPIRO groups plasma aldosterone increased 4.7-fold and 7.3-fold respectively, which allowed confirmation of adequacy of

Table 1. Physiological Data of 8-Week Old Wistar Rats During Aldosterone (ALDO), Spironolactone (SPIRO), Aldosterone Plus Spironolactone (ALDO+SPIRO) Treatments and Corresponding Placebo Values

\begin{tabular}{|c|c|c|c|c|c|c|}
\hline & $\begin{array}{l}\text { PALDO } \\
(n=5)\end{array}$ & $\begin{array}{l}\text { ALDO } \\
(n=5)\end{array}$ & $\begin{array}{l}\text { PSPIRO } \\
(n=4)\end{array}$ & $\begin{array}{l}\text { SPIRO } \\
(n=4)\end{array}$ & $\begin{array}{c}\text { PALDO+PSPIRO } \\
(n=5)\end{array}$ & $\begin{array}{c}\text { ALDO+SPIRO } \\
(n=5)\end{array}$ \\
\hline Initial BW (g) & $193.4 \pm 3.1$ & $201.2 \pm 1.5$ & $205.5 \pm 5.0$ & $208.5 \pm 1.7$ & $201.6 \pm 3.0$ & $216.4 \pm 2.3^{*}$ \\
\hline Final BW (g) & $228.2 \pm 2.5$ & $242.8 \pm 3.4^{*}$ & $241.3 \pm 4.9$ & $247.0 \pm 2.8$ & $245.6 \pm 4.8$ & $258.8 \pm 3.4 *$ \\
\hline Systolic blood pressure (mm Hg) & $127.7 \pm 1.4$ & $137.0 \pm 3.2 *$ & $129.9 \pm 1.4$ & $131.0 \pm 2.9$ & $128.9 \pm 1.0$ & $134.7 \pm 1.2$ \\
\hline Diastolic blood pressure (mm Hg) & $80.2 \pm 1.0$ & $81.2 \pm 5.5$ & $75.5 \pm 5.5$ & $81.6 \pm 1.4$ & $79.2 \pm 1.7$ & $82.7 \pm 5.3$ \\
\hline Heart rate (beats per min) & $394.5 \pm 18.5$ & $405.2 \pm 16.3$ & $410.5 \pm 16.5$ & $407.9 \pm 23.3$ & $434.9 \pm 9.4$ & $432.4 \pm 13.4$ \\
\hline LKW (g) & $0.725 \pm 0.02$ & $0.795 \pm 0.03$ & $0.770 \pm 0.013$ & $0.759 \pm 0.004$ & $0.732 \pm 0.009$ & $0.824 \pm 0.02 *$ \\
\hline LKW/BW (\%) & $0.318 \pm 0.01$ & $0.327 \pm 0.01$ & $0.319 \pm 0.01$ & $0.308 \pm 0.003$ & $0.298 \pm 0.003$ & $0.319 \pm 0.01$ \\
\hline Plasma $\mathrm{Na}^{+}(\mathrm{mmol} / \mathrm{l})$ & $136.8 \pm 1.4$ & $136.6 \pm 1.1$ & $138.6 \pm 1.4$ & $135.2 \pm 2.0$ & $137.2 \pm 0.2$ & $136.0 \pm 0.3$ \\
\hline Plasma Cl (mmol/l) & $91.2 \pm 0.7$ & $86.8 \pm 1.0 *$ & $92.8 \pm 1.1$ & $88.6 \pm 0.9^{*}$ & $97.0 \pm 1.0$ & $96.6 \pm 0.7$ \\
\hline Plasma urea (mg/dl) & $25.0 \pm 1.8$ & $26.4 \pm 1.2$ & $24.8 \pm 1.2$ & $22.2 \pm 2.1$ & $29.4 \pm 1.4$ & $34.8 \pm 2.3$ \\
\hline Plasma creatinine (mg/dl) & $0.28 \pm 0.01$ & $0.25 \pm 0.01 *$ & $0.30 \pm 0.01$ & $0.29 \pm 0.01$ & $0.31 \pm 0.01$ & $0.31 \pm 0.01$ \\
\hline Osmolality $\left(\mathrm{Osm} / \mathrm{kg} \mathrm{H}_{2} \mathrm{O}\right)$ & $449.4 \pm 20.1$ & $476.8 \pm 21.0$ & $448.0 \pm 27.2$ & $438.8 \pm 32.3$ & $369.0 \pm 15.1$ & $353.8 \pm 11.5$ \\
\hline Plasma aldosterone $(\mathrm{pg} / \mathrm{ml})$ & $41.9 \pm 17.5$ & $195.0 \pm 58.2 *$ & $17.8 \pm 3.5$ & $31.9 \pm 7.5$ & $30.9 \pm 3.0$ & $224.1 \pm 38.1 *$ \\
\hline PRA (pg/ml) & $1.5 \pm 0.3$ & $0.9 \pm 0.1$ & $1.8 \pm 0.4$ & $1.2 \pm 0.2$ & $1.0 \pm 0.2$ & $1.2 \pm 0.1$ \\
\hline
\end{tabular}

Values are mean \pm SEM $(n=4-5)$.

Significantly different from values for the corresponding placebo $(* \mathrm{P}<0.05)$.

Body Weight (BW), Left Kidney Weight (LKW) and Left Kidney Weight /Body Weight (LKW/BW). 
treatments (Table 1). Plasma levels of aldosterone were similar across the placebo-implanted groups. Plasma levels of sodium and urea, plasma osmolarity and PRA were not affected by any of the treatments. Plasma levels of chloride and creatinine in ALDO group were significantly lower than those of placebo-treated rats. In the SPIRO group the plasma chloride concentration was also decreased then compared to the corresponding placebo group. The systolic blood pressure in the ALDO and the ALDO+SPIRO groups was found to be significantly higher at the end of the study, whereas in the SPIRO group systolic blood pressure did not differ. The diastolic blood pressure and heart rate were not affected by the treatments (Table 1).

\section{Effect of Aldosterone Treatment on the Expression Of Several Amino Acid Transporters}

Evaluation of amino acid transporters mRNA expression was performed by quantitative real time RT-PCR and no significant changes were found on the mRNA expression of renal cortical LAT1 and 4F2hc in ALDO, SPIRO and ALDO+SPIRO groups (Fig. 1A and 1C). ALDO group was endowed with significantly higher renal cortical LAT2 mRNA levels $(44.6 \pm 9.8 \%$ increase) than that of the corresponding placebo (Fig. 1B). This increase in LAT2 mRNA level was not observed when aldosterone was combined with the competitive mineralocorticoid receptor blocker spironolactone (Fig. 1B). LAT2 mRNA levels in the SPIRO group were similar to those of corresponding placebo (Fig. 1B). Renal $\mathrm{Na}^{+}$-dependent amino acid transporter ASCT2

\section{A}

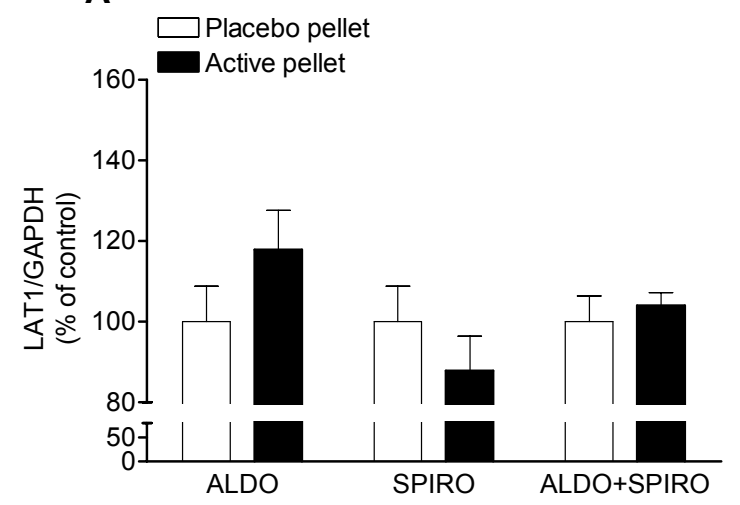

\section{C}

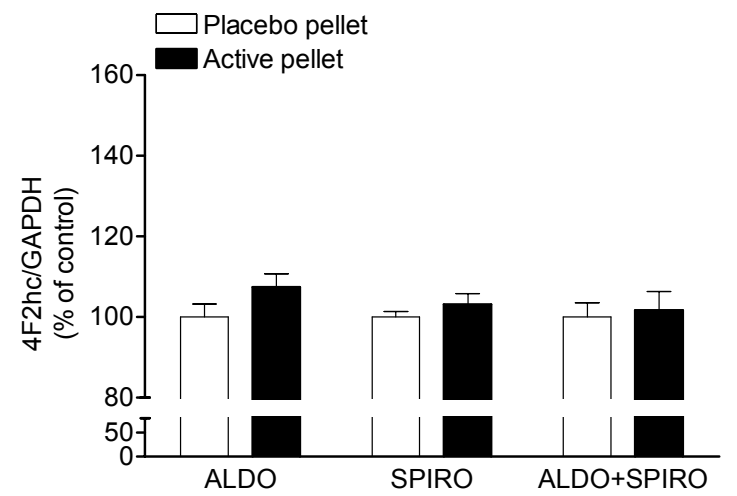

transcript abundance was not affected by any of the treatments (Fig. 1D).

Protein expression of LAT1, LAT2, 4F2hc and ASCT2 was evaluated by immunoblot analysis in the renal cortical membranes of ALDO and ALDO+SPIRO groups. The protein expression level of $\mathrm{Na}^{+}$-independent amino acid transporters LAT1 and LAT2 in renal cortical membranes from the ALDO group was $20 \%$ lower than that in placebo-treated rats, but this did not attained a statistically significant difference (Fig. 2A and 2C). In the ALDO+SPIRO group LAT1 and LAT2 protein abundance was similar to corresponding placebo group (Fig. 2B and 2D). The expression of renal $4 \mathrm{~F} 2 \mathrm{hc}$ protein in the ALDO group was significantly lower $(\sim 51.3 \%$ decrease) than that in placebo group (Fig. 2E). This effect was not prevented by spironolactone (Fig. 2F). Considering that $4 \mathrm{~F} 2 \mathrm{hc}$ is required for LAT2 to be functional, the LAT2/4F2hc reveals the functionality of the transporter. LAT2/4F2hc ratios were obtained by simultaneous quantification of LAT2 and 4F2hc protein expression from the same blots. The renal LAT2/4F2hc protein ratios in aldosteronetreated rats $(1.07 \pm 0.08)$ were significantly $(\mathrm{P}<0.05)$ increased when compared to the corresponding placebo group $(0.64 \pm 0.01)$.

In the ALDO and ALDO+SPIRO groups, the $\mathrm{Na}^{+}-$ dependent amino acid transporter ASCT2 expression was found not to differ from corresponding placebo groups (Fig. $2 \mathbf{G}$ and $\mathbf{2 H}$ ).

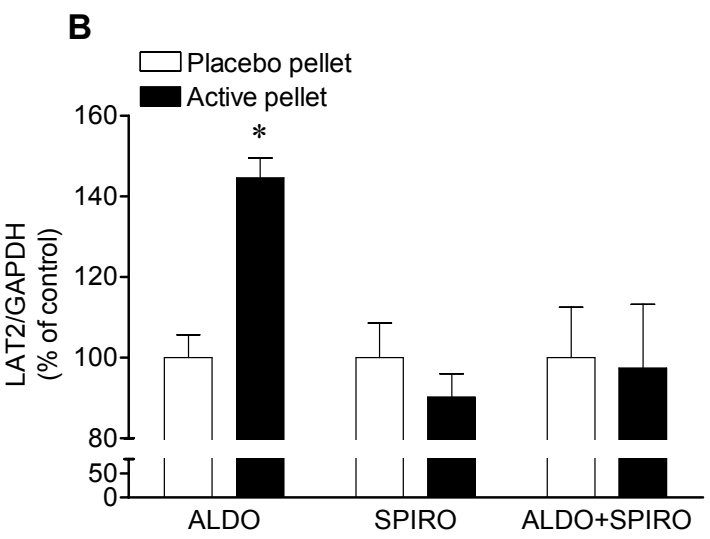

D

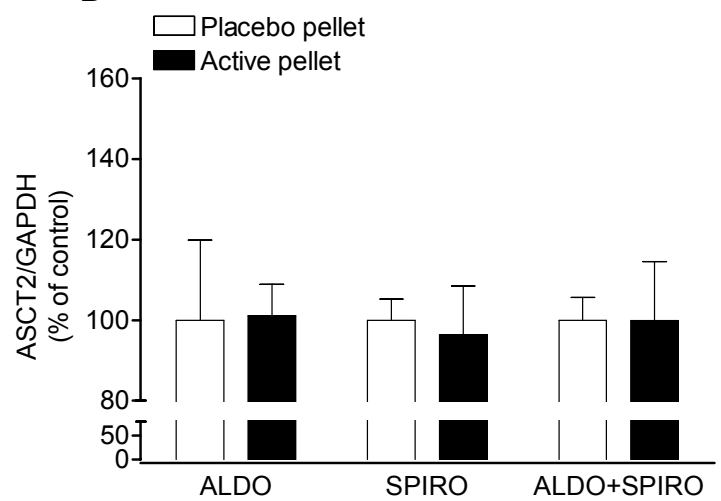

Fig. (1). Transcript abundance of renal cortical (A) LAT1, (B) LAT2, (C) 4F2hc and (D) ASCT2, in 8-week old Wistar rats subcutaneously implanted with aldosterone (ALDO), spironolactone (SPIRO), aldosterone plus spironolactone (ALDO+SPIRO) or corresponding placebo pellets, for 8 days. mRNA quantification by real-time PCR. Columns represent means of 4-6 determinations per group and vertical lines show SEM. Significantly different from placebo $(* \mathrm{P}<0.05)$. 

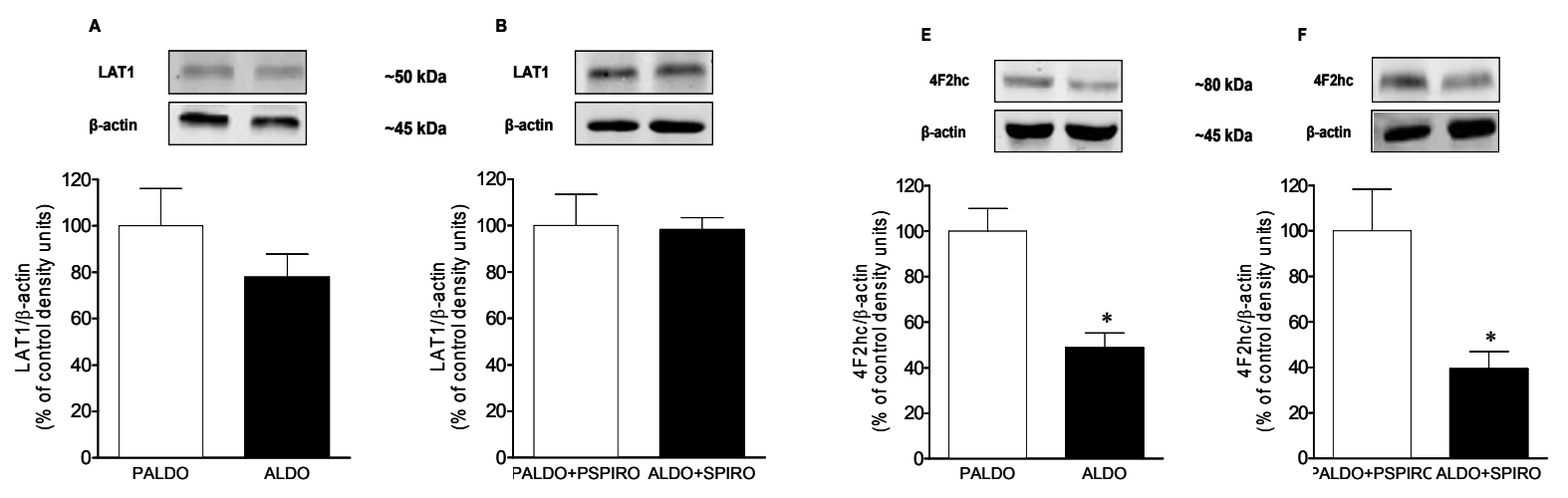

C
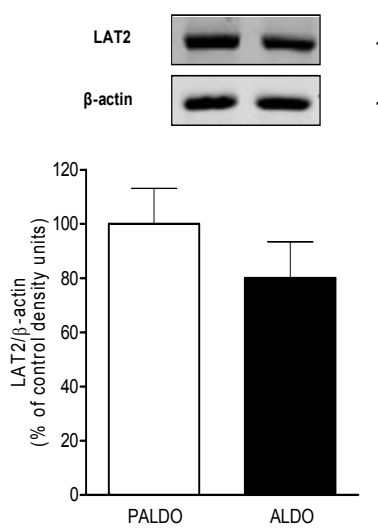

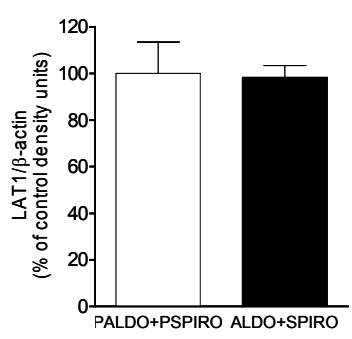

D
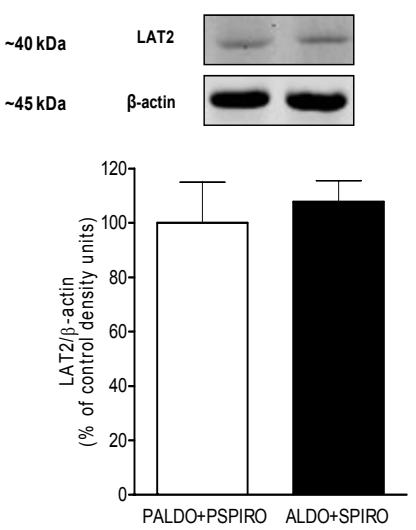

G
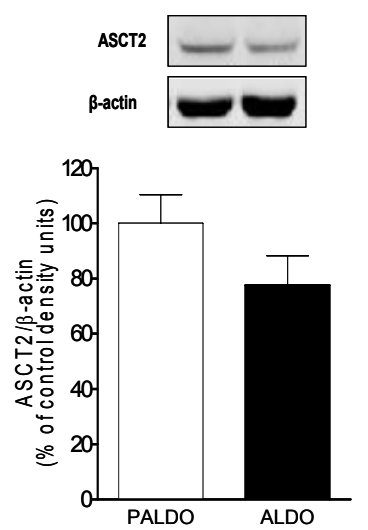

H
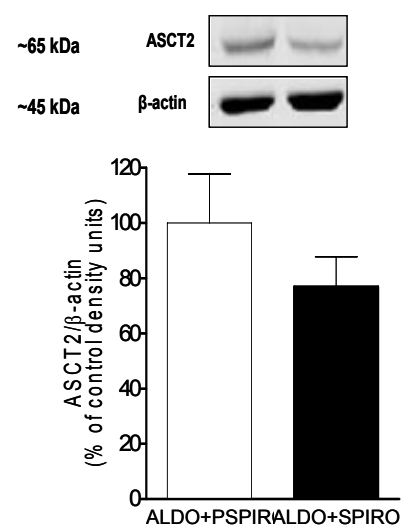

Fig. (2). Renal cortical (A and B) LAT1, (C and D) LAT2, (E and F) 4F2hc and (G and H) ASCT2 protein expression in 8-week old Wistar rats subcutaneously implanted with aldosterone (ALDO), aldosterone plus spironolactone (ALDO+SPIRO) or placebo pellets (PALDO and PALDO+PSPIRO), for 8 days. Columns represent means of 4-6 determinations per group and vertical lines show SEM. Significantly different from placebo $(* \mathrm{P}<0.05)$.

The discrepancy between mRNA levels and protein expression might be related to post-transcriptional events. Several levels of nuclear post-transcriptional events can be regulated, such as the control of splicing efficiency, precursor RNA stability, polyadenylation or RNA transport [23].

\section{Effect of Aldosterone Treatment on Renal Dopaminergic System}

Fig. (3) depicts changes in the urinary excretion of dopamine and DOPAC in rats treated with ALDO, SPIRO and ALDO+SPIRO. In the ALDO group, both dopamine and DOPAC urinary excretion was significantly $(\mathrm{P}<0.05)$ decreased when compared to the corresponding placebo. The urinary excretion of dopamine was similar to placebo in the SPIRO and ALDO+SPIRO groups.

\section{DISCUSSION}

LAT2 is a major $\mathrm{Na}^{+}$-independent amino acid transporter with marked expression in transporting epithelia, namely in the kidney [24-26]. Chronic treatment with aldosterone increased renal LAT2 transcript abundance, which was reversed by the mineralocorticoid receptor antagonist spironolactone. This finding suggests the possible involvement of the antinatriuretic hormone aldosterone in the regulation of this $\mathrm{Na}^{+}$-independent amino acid transporter. This would provide a mean for $\mathrm{Na}^{+}$to indirectly interfere with the expression and function of $\mathrm{Na}^{+}$-independent transporters. It is well known that aldosterone controls sodium excretion by regulating its reabsorption across tight epithelia such as the distal nephron. Spindler and colleagues [4] reported that Xenopus leavis ASUR4 (homologue of human LAT1), whose function is not yet known, was one of the early aldosterone upregulated RNAs by differential display PCR in A6 cells. Still, ASUR4 was mentioned in the context of the late response despite a twofold increase at the mRNA level in the course of response to aldosterone. This correlates positively with the fact that ASUR4 appears to be a constitutive element that potentially exerts a supportive role for the anabolic actions of aldosterone [27]. It is in this late phase that increment of LAT2 mRNA levels produced by aldosterone should be integrated. This would provide a mean to indirectly control the synthesis of dopamine and consequently promote a negative feedback to its primary actions. It is known that aldosterone works in concert with a large number of other hormones and factors also implicated in the control of sodium and volume homeostasis and blood pressure via a complex network of regulatory cascades [27].

Nevertheless, the functionality of LAT2 is dependent on the abundance of $4 \mathrm{~F} 2 \mathrm{hc}[24,26,28]$. Distinct from the aldosterone-induced increases in LAT2 mRNA, no changes were found to occur in renal $4 \mathrm{~F} 2 \mathrm{hc}$ mRNA abundance. Besides, aldosterone-induced increase on LAT2 transcript abundance was accompanied by a slight decrease in LAT2 protein abundance, whereas aldosterone treatment markedly reduced the abundance of $4 \mathrm{~F} 2 \mathrm{hc}$, but this effect was not reversed by spironolactone. Accordingly, aldosterone may modulate the 
A

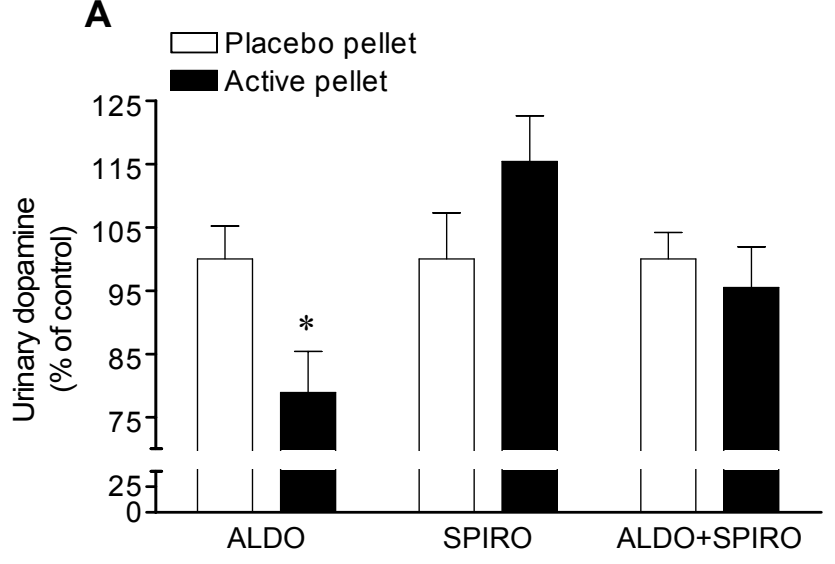

B

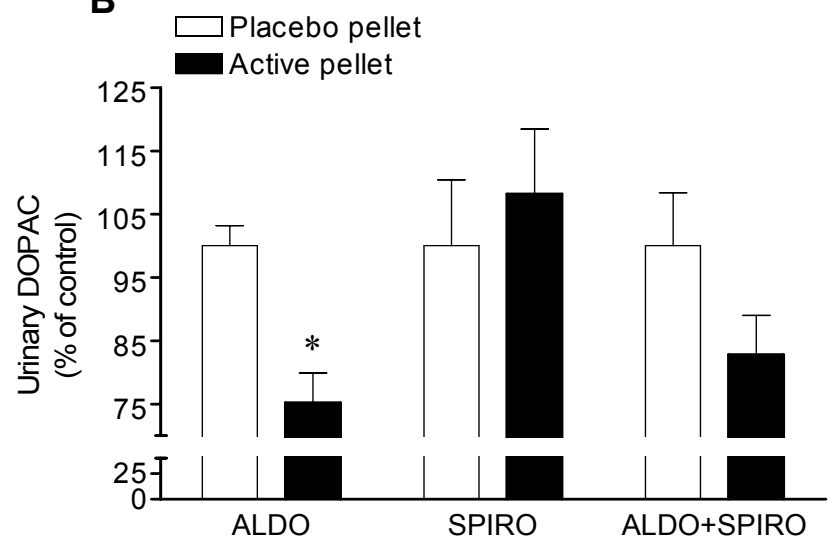

Fig. (3). Urinary levels of dopamine and DOPAC in 8-week old Wistar rats subcutaneously implanted with aldosterone (ALDO), aldosterone plus spironolactone (ALDO+SPIRO) or placebo pellets (PALDO and PALDO+PSPIRO), for 8 days. Columns represent means of 6 determinations per group and vertical lines show SEM. Significantly different from placebo $(* \mathrm{P}<0.05)$. Absolute urinary levels (in $\mathrm{nmol} / 24 \mathrm{~h})$ of dopamine and DOPAC were $10.7 \pm 0.7$ and $23.9 \pm 1.4$, respectively.

expression of LAT2 and 4F2hc by different mechanisms. Therefore, since $4 \mathrm{~F} 2 \mathrm{hc}$ is essential for the function of LAT2 $[24,26,28]$, increases in renal LAT2/4F2hc protein ratios in the aldosterone-treated rats may actually translate into a decrease in LAT2 functionality [14]. This is most evidenced by the reduction of urinary dopamine and DOPAC in the aldosterone-treated group, given that LAT2 promotes the transport of dopamine precursor L-DOPA $[12,13]$. Interestingly, these aldosterone-treated rats showed an increase in blood pressure, which was reversed by the co-administration of the competitive mineralocorticoid receptor blocker spironolactone. Therefore, this increase in blood pressure might be a consequence of the excess of aldosterone and the lower dopamine production observed in this group.

The regulation of $4 \mathrm{~F} 2 \mathrm{hc}$ and light chains has been explored in a small number of studies with conflicting results. Broer et al. [29] found increased 4F2hc mRNA levels and enhanced L-type amino acid transport activity in phorbol esters-treated lymphocytes. The glucocorticoid dexamethasone was found to induce both the activity and expression of $4 \mathrm{~F} 2 \mathrm{hc}$ in the rat kidney [2]. Arginine depletion increased TA1/LAT1 mRNA expression, accompanied with no appreciable response of $4 \mathrm{~F} 2 \mathrm{hc}$ in rat hepatic cell lines [30]. In cultured human placental choronic villi Kudo and Boyd [31] found that system $\mathrm{L}$ and $\mathrm{y}^{+} \mathrm{L}$ activities correlate positively with increases in the expression of 4F2hc. Despite the limited information available on the regulation of system $\mathrm{L}$, $4 \mathrm{~F} 2 \mathrm{hc}$ is well recognized as a multifunctional protein that is not only responsible for the functional expression of transporters, but also linked to several signalling pathways [32]. In fact, several lines of evidence indicate that 4F2hc interacts with integrins [33], which have been shown to be one of the early downregulated transcripts by aldosterone [34]. Therefore, it is possible that the association of signalling molecules to 4F2hc may also affect the activity of 4F2hc associated amino acid transporters [32]. Though it could be hypothesized that increases in LAT2 mRNA by aldosterone may constitute a compensatory mechanism for the suggested decrease in LAT2 functionality, there is evidence suggesting that this may not be the case. It should be kept in mind that the effects of aldosterone upon LAT2 transcript were medi- ated through spironolactone-sensitive mechanisms, whereas those upon $4 \mathrm{~F} 2 \mathrm{hc}$ were insensitive to spironolactone. It is, therefore, possible that decreases in $4 \mathrm{~F} 2 \mathrm{hc}$ protein abundance by aldosterone may constitute either a non-genomic effect or an indirect effect of the hormone. The extent to which these two events (the increase in LAT2 transcript abundance and the decrease in 4F2hc protein) occur in parallel or are related to each other as compensatory mechanisms is under investigation.

In contrast to LAT2, renal LAT1 transcript was not affected by aldosterone administration. This $\mathrm{Na}^{+}$-independent amino acid transporter has a very weak expression in the kidney and its exact localization along the nephron is not known. LAT1 expression was found to occur in brain capillary endothelial cells; therefore, it is likely that LAT1 may be expressed in the vasculature of kidney. Endothelial cells express mineralocorticoid receptors and, recently, it was shown that aldosterone led to sustained cell swelling, which was sensitive to inhibition by spironolactone [35]. Within a few minutes, cells were found to respond to aldosterone treatment with a concomitant increased in the cell surface [35]. LAT1 is involved in cell growth, providing cells with essential amino acids and, for such a reason, it was expected that aldosterone might change renal LAT1 expression. However, it should be mentioned that the effects of aldosterone upon endothelial cell growth are "early aldosterone events". In fact, it was observed that after reaching a maximum, cell volume returned back to the original volume (10-15 min after aldosterone secretion) [35].

ASCT2 was unaffected by aldosterone, which fits well with the lack of correlation between the changes in plasma aldosterone levels and renal ASCT2 mRNA expression, observed in 12-week old SHR on HS intake [14]. It is suggested that other factors might be responsible for the modulation of this $\mathrm{Na}^{+}$-dependent amino acid transport. ASCT2 has been shown to be regulated by nitric oxide (NO) in the human intestinal cell line Caco-2 [36]. Growth factors, like epidermal growth factor (EGF) and growth hormone [33], have also been found to induce sodium-dependent neutral amino acid transporter ASCT2 mRNA expression in rabbit 
intestine [37]. Furthermore, the expression of the ASCT2 transporter in HepG2 hepatoma cells is stimulated by glutamine by a pathway involving the promoter element AGGTGAATGACTT which binds FXR/RXR dimmers [38].

In conclusion, increases in renal LAT2 transcript during chronic treatment with aldosterone occur through a spironolactone-sensitive genomic mechanism. This effect parallels with a decrease in LAT2 functionality, resulting from decreases in $4 \mathrm{~F} 2 \mathrm{hc}$ protein abundance, which appears to be either a non-genomic effect of aldosterone or an indirect effect of the hormone. The decrease in LAT2 functionality in aldosterone-treated rats correlates well with the reduction in urinary dopamine, which is in line with the finding that LAT2 overexpression in the SHR kidney is accompanied by an increased ability to produce dopamine.

\section{ACKNOWLEDGMENT}

Supported by Fundação para a Ciência e a Tecnologia and Programa de Investimentos e Despesas de Desenvolvimento da Administração Central (PIDDAC) (PIC/IC/83204/2007).

\section{ABBREVIATIONS}

$$
\begin{array}{ll}
\text { DEPC } & \text { Diethylpyrocarbonate } \\
\text { DOPAC } & =3,4 \text {-dihydroxyphenylacetic acid } \\
\text { PRA } & =\text { Plasma renin activity } \\
\text { PTE } & =\text { Proximal tubular epithelial } \\
\text { sgk } & =\text { Serum- and glucocorticoid-regulated kinase }
\end{array}
$$

\section{REFERENCES}

[1] Fleck C, Schwertfeger M, Taylor PM. Regulation of renal Amino Acid (AA) transport by hormones, drugs and xenobiotics - a review. Amino Acids 2003; 24(4): 347-74.

[2] Schwertfeger M, Roskos M, Fleck C. Identification of the site of glucocorticoid action on neutral amino acid transport in superficial nephrons of rat kidney. Amino Acids 2000; 18(3): 279-88.

[3] Schwertfeger M, Pissowotzki K, Fleck C, Taylor PM. Regulation of L-leucine transport in rat kidney by dexamethasone and triiodothyronine. Amino Acids 2003; 25(1): 75-83.

[4] Spindler B, Mastroberardino L, Custer M, Verrey F. Characterization of early aldosterone-induced RNAs identified in A6 kidney epithelia. Pflugers Arch 1997; 434(3): 323-31.

[5] Wagner CA, Lang F, Broer S. Function and structure of heterodimeric amino acid transporters. Am J Physiol Cell Physiol 2001; 281(4): C1077-93.

[6] Gomes P, Soares-da-Silva P. Na+-independent transporters, LAT-2 and $\mathrm{b} 0,+$, exchange L-DOPA with neutral and basic amino acids in two clonal renal cell lines. J Membr Biol 2002 15; 186(2): 63-80.

[7] Soares-da-Silva P, Serrao MP. High- and low-affinity transport of L-leucine and L-DOPA by the hetero amino acid exchangers LAT1 and LAT2 in LLC-PK1 renal cells. Am J Physiol Renal Physiol 2004; 287(2): F252-F61.

[8] Soares-da-Silva P, Serrao MP. Apical and basolateral 4F2he and the amino acid exchange of L-DOPA in renal LLC-PK 1 cells. Amino Acids 2005; 29(3): 213-9.

[9] Soares-da-Silva P, Serrao MP, Pinho MJ, Bonifacio MJ. Cloning and gene silencing of LAT2, the L-3,4-dihydroxyphenylalanine (LDOPA) transporter, in pig renal LLC-PK1 epithelial cells. FASEB J 2004; 18(13): 1489-98.

[10] Soares-da-Silva P, Serrao MP, Vieira-Coelho MA. Apical and basolateral uptake and intracellular fate of dopamine precursor Ldopa in LLC-PK1 cells. Am J Physiol 1998; 274(2 Pt 2): F243F51.

[11] Soares-da-Silva P, Serrao P, Fraga S, Pinho MJ. Expression and function of LAT1, a neutral amino acid exchanger, in renal porcine epithelial cell line LLC-PK. . Acta Physiol Scand 2005; 185(1): 718.
[12] Pinho MJ, Serrao MP, Gomes P, Hopfer U, Jose PA, Soares-daSilva P. Over-expression of renal LAT1 and LAT2 and enhanced L-DOPA uptake in SHR immortalized renal proximal tubular cells. Kidney Int 2004; 66(1): 216-26.

[13] Pinho MJ, Gomes P, Serrao MP, Bonifacio MJ, Soares-da-Silva P. Organ-specific overexpression of renal LAT2 and enhanced tubular L-DOPA uptake precede the onset of hypertension. Hypertension 2003; 42(4): 613-8.

[14] Pinho MJ, Serrao MP, Soares-da-Silva P. High salt intake and the renal expression of amino acid transporters in spontaneously hypertensive rats. Am J Physiol Renal Physiol 2007; 292: F1452-F63.

[15] Alvelos M, Ferreira A, Bettencourt P, et al. The effect of dietary sodium restriction on neurohumoral activity and renal dopaminergic response in patients with heart failure. Eur J Heart Fail 2004; 6(5): 593-9.

[16] Ferreira A, Bettencourt P, Dias P, et al. Neurohormonal activation, the renal dopaminergic system and sodium handling in patients with severe heart failure under vasodilator therapy. Clin Sci (Lond) 2001; 100(5): 557-66.

[17] Ferreira A, Bettencourt P, Pimenta J, et al. The renal dopaminergic system, neurohumoral activation, and sodium handling in heart failure. Am Heart J 2002; 143(3): 391-7.

[18] Rocha R, Chander PN, Khanna K, Zuckerman A, Stier CT Jr. Mineralocorticoid blockade reduces vascular injury in stroke-prone hypertensive rats. Hypertension 1998; 31 (1 Pt 2): 451-8.

[19] Rocha R, Chander PN, Zuckerman A, Stier CT Jr. Role of aldosterone in renal vascular injury in stroke-prone hypertensive rats. Hypertension 1999; 33(1 Pt 2): 232-7.

[20] Rocha R, Stier CT Jr, Kifor I, et al. Aldosterone: a mediator of myocardial necrosis and renal arteriopathy. Endocrinology 2000; 141(10): 3871-8.

[21] Soares-da-Silva P, Fernandes MH, Pinto-do-Ó PC. Cell inward transport of L-DOPA and 3-O-methyl-L-DOPA in rat renal tubules. Br J Pharmacol 1994; 112(2): 611-5.

[22] Soares-da-Silva P, Pestana M, Fernandes MH. Involvement of tubular sodium in the formation of dopamine in the human renal cortex. J Am Soc Nephrol 1993; 3(9): 1591-9.

[23] Akker SA, Smith PJ, Chew SL. Nuclear post-transcriptional control of gene expression. J Mol Endocrinol 2001; 27: 123-31.

[24] Pineda M, Fernandez E, Torrents D, et al. Identification of a membrane protein, LAT-2, that Co-expresses with 4F2 heavy chain, an L-type amino acid transport activity with broad specificity for small and large zwitterionic amino acids. J Biol Chem 1999; 274(28): 19738-44.

[25] Rossier G, Meier C, Bauch C, et al. LAT2, a new basolateral $4 \mathrm{~F} 2 \mathrm{hc} / \mathrm{CD} 98$-associated amino acid transporter of kidney and intestine. J Biol Chem 1999; 274(49): 34948-54.

[26] Segawa H, Fukasawa Y, Miyamoto K, Takeda E, Endou H, Kanai $\mathrm{Y}$. Identification and functional characterization of a $\mathrm{Na}-$ independent neutral amino acid transporter with broad substrate selectivity. J Biol Chem 1999; 274(28): 19745-51.

[27] Verrey F. Early aldosterone action: toward filling the gap between transcription and transport. Am J Physiol 1999; 277(3 Pt 2): F319F27.

[28] Nakamura E, Sato M, Yang H, et al. 4F2 (CD98) heavy chain is associated covalently with an amino acid transporter and controls intracellular trafficking and membrane topology of 4F2 heterodimer. J Biol Chem 1999; 274(5): 3009-16.

[29] Broer S, Broer A, Hamprecht B. Expression of the surface antigen 4F2hc affects system-L-like neutral-amino-acid-transport activity in mammalian cells. Biochem J 1997; 324: 535-41.

[30] Campbell WA, Sah DE, Medina MM, Albina JE, Coleman WB, Thompson NL. TA1/LAT-1/CD98 light chain and system L activity, but not 4F2/CD98 heavy chain, respond to arginine availability in rat hepatic cells. Loss Of response in tumor cells. J Biol Chem 2000; 275(8): 5347-54.

[31] Kudo Y, Boyd CA. Heterodimeric amino acid transporters: expression of heavy but not light chains of CD98 correlates with induction of amino acid transport systems in human placental trophoblast. J Physiol 2000; 523(Pt 1): 13-8.

[32] Kanai Y, Endou H. Heterodimeric amino acid transporters: molecular biology and pathological and pharmacological relevance. Curr Drug Metab 2001; 2(4): 339-54.

[33] Fenczik CA, Sethi T, Ramos JW, Hughes PE, Ginsberg MH. Complementation of dominant suppression implicates CD98 in integrin activation. Nature 1997; 390(6655): 81-5. 
[34] Gumz ML, Popp MP, Wingo CS, Cain BD. Early transcriptional effects of aldosterone in a mouse inner medullary collecting duct cell line. Am J Physiol Renal Physiol 2003; 285(4): F664-73.

[35] Oberleithner H, Schneider SW, Albermann L, et al. Endothelial cell swelling by aldosterone. J Membr Biol 2003; 196(3): 163-72.

[36] Uchiyama T, Matsuda Y, Wada M, Takahashi S, Fujita T. Functional regulation of $\mathrm{Na}$-dependent neutral amino acid transporter ASCT2 by S-nitrosothiols and nitric oxide in Caco-2 cells. FEBS Lett 2005; 579(11): 2499-506.
[37] Avissar NE, Ziegler TR, Wang HT, et al. Growth factors regulation of rabbit sodium-dependent neutral amino acid transporter ATB0 and oligopeptide transporter $1 \mathrm{mRNAs}$ expression after enteretomy. J Parenter Enteral Nutr 2001; 25(2): 65-72.

[38] Bungard CI, McGivan JD. Identification of the promoter elements involved in the stimulation of ASCT2 expression by glutamine availability in HepG2 cells and the probable involvement of FXR/RXR dimers. Arch Biochem Biophys 2005; 443(1-2): 53-9.

Received: May 20, 2009

(C) Pinho et al.; Licensee Bentham Open.

This is an open access article licensed under the terms of the Creative Commons Attribution Non-Commercial License (http://creativecommons.org/licenses/by-nc/3.0/) which permits unrestricted, non-commercial use, distribution and reproduction in any medium, provided the work is properly cited. 